\title{
Molecular Interaction Studies between Methylamine and 2-Nitrobenzoic Acid by Quantum Chemical Calculation (FT-IR, FMO, GCRD, MEP, NLO) and Dielectric Relaxation Analysis
}

\author{
M. Aravinthraj ${ }^{1}$, F. Liakath Ali Khan ${ }^{2}$, J. Udayaseelan ${ }^{3}$, R. Santhosh Kumar $^{4}$ \\ ${ }^{1,2}$ Department of Physics, Islamiah College (Autonomous), Vaniyambadi, Tamil Nadu \\ ${ }^{3}$ Department of Physics, Government Thirumagal Mills College, Gudiyatam, Tamil Nadu \\ ${ }^{4}$ Department of Physics, Sacred Heart College (Autonomous), Tirupattur, Tamil Nadu \\ *Corresponding Author: m.aravinthraj@gmail.com
}

Available online at: www.isroset.org

Received: 22/May/2019, Accepted: 19/Jun/2019, Online: 30/Jun/2019

\begin{abstract}
The FTIR spectrum of methylamine with 2-nitrobenzoic acid (ma2nba) in liquid phase is recorded and the comprehensive vibrational assignments and PED is attained by the vibrational energy distribution analysis. Ma2cba was theoretically optimized and FMO, nonlinear optical, molecular surfaces and comparison between Mulliken and natural charges were also performed by DFT method with B3LYP/6-311++G(d,p) basis set. The charge transfers in the molecule confirmed by the HOMO and lowest LUMO. Dielectric relaxation parameters like dielectric constant, dielectric loss, average and overall relaxation time, molar free energy of activation for viscous flow and the molar free energy of dielectric relaxation of ma2nba have been calculated over five different molar ratios $(1: 3,1: 2,1: 1,2: 1,3: 1)$ at room temperature by Higasi's method. These parameters are inferred in terms of molecular association and dipolar orientation. Moreover, the relaxation time found maximum at 1:1 molar ratio.
\end{abstract}

Keywords-Quantum Chemical Calculations, B3LYP, HOMO, LUMO, DOS, NBO, NLO, Dielectric Relaxation

\section{INTRODUCTION}

Studying molecular interactions between binary or ternary mixtures, especially determining intermolecular and intramolecular forces of attraction are playing an important role, because they are helpful in determining the molecular properties like their density, viscosity, boiling point, melting point, vaporization and fusion enthalpies. In addition, weak forces are electrostatic in nature; they arose between positively and negatively charged species. When the distance between the molecules increases, electrostatic interactions fall off in haste. Moreover, determining weaker interactions are important for liquids especially when the molecules are close [1].

In this study, we explicitly focused on determining intermolecular interactions between methylamine and 2nitrobenzoic acid. Because, methylamines are directly used as raw materials or as catalysts to manufacture other compounds for catalytic activity. Fuel additives are generally used to enhance performance of the engine in a diverse ways. Methylamines are preferred to manufacture intermediates to make pharmaceuticals in a diverse way [2-3]. And 2nitrobenzoic acid is engaged as a synthetic reagent and can function as a growth supplement for pseudomonas fluorescens strain KU-7. It is also used as a reagent for protecting amine groups in the organic synthesis [4-5]. In addition, DFT method is employed for the mixture due to its great accurateness in replicating the experimental values of molecule geometry, vibrational frequencies, atomic charges, FMO, MEP and NLO properties, etc. [6-9]. Related to this phenomenon, we wish to present here the spectroscopic properties of methylamine with 2-nitro benzoic acid. The first order hyperpolarizability, HOMO, LUMO, and NBO analyses have been used to elucidate the information regarding charge transfer within the molecule. This paper is organized in the following order. Section II of this papers gives information about materials and methods adopted for the study, in that first method is based on quantum computational method and second method is about dielectric relaxation method and also provides the necessary theory. And section III gives detailed description about the results and discussion of both computational and dielectric relaxation method. Section IV concluded the research work with the obtained results.

\section{MATERIALS AND METHOD}

Analar grade chemicals of Methylamine, 1,4-Dioxane are purchased from E-Merck and 2 - Nitro benzoic acid 
obtained from sigma Aldrich. Moreover, the chemicals are used directly without purification.

\subsection{Computational method}

The entire computational calculations are performed with the help of Gaussian $09 \mathrm{~W}$ program [10] with DFT(B3LYP)/ 6$311++\mathrm{G}(\mathrm{d}, \mathrm{p})$ basic set and the combined structure of methylamine and 2-nitrobenzoic acid (ma2nba) is optimized. From optimized structure, the bond length, bond angle, dihedral angle are theoretically determined. The vibrational frequencies are determined and the frequencies are scaled by using 0.9684 for DFT(B3LYP)/6-311++G(d,p) [11]. The FTIR spectrum of ma2nba has been recorded in the region 450-4000 $\mathrm{cm}^{1}$ on a Perkin Elmer system one FTIR spectrometer. Frontier molecular orbit, Global chemical reactivity descriptor, MEP, Contour map, HOMO and LUMO energy levels, Mulliken population analysis, Natural charges and NLO properties are calculated with the help of optimized structure [12]. The vibrational assignments are performed using VEDA 4.0 software [13] program.

\subsection{Dielectric relaxation method}

The static dielectric constants $\left(\varepsilon_{0}\right)$ are measured by heterodyne beat method in the room temperature using a Dipole meter. The refractive index measured by using Abbe's refractometer. The measurement of dielectric constant $\left(\varepsilon^{\prime}\right)$ at an angular frequency and dielectric loss $\left(\varepsilon^{\prime \prime}\right)$ are carried in the X-band microwave frequency of $9.43 \mathrm{GHz}$. Using the experimental dielectric data, dielectric constant $\left(\varepsilon^{\prime}\right)$, dielectric loss $\left(\varepsilon^{\prime \prime}\right)$, average relaxation time $\left(\tau_{1}\right)$, overall dielectric relaxation $\left(\tau_{2}\right)$, The molar free energy of activation for viscous flow $(\Delta \mathrm{f} \eta)$ and the molar free energy of dielectric relaxation $(f \Delta \tau)$ of ma2nba have been calculated over five different molar ratios $(1: 3,1: 2,1: 1,2: 1,3: 1)$ at room temperature. The viscosities are measured with the help of Oswald's viscometer at room temperature. Methyl amine and 2-nitrobenzoic acid were separately dissolved at the same molar concentration $(0.3 \mathrm{~mol} / \mathrm{L})$ in the solvent $1,4-$ Dioxane. Their dielectric constants are measured separately. Then the two solutions are mixed in different proportions at constant measurements. As the maximum deviation of dielectric constant for all the systems occurs at equimolar ratio of the solutes, it is presumed that the deviation is due to the formation of 1:1 complexes.

\subsection{Theory}

The dielectric constant $\varepsilon^{\prime}$ and $\varepsilon^{\prime \prime}$ of polar molecules in the form of dilute solutions with a non-polar molecules are represented by the following equations [14].

$$
\begin{aligned}
& \varepsilon_{0}=\varepsilon_{10}+a_{0} \omega_{2} \\
& \varepsilon^{\prime}=\varepsilon_{1}^{\prime}+a^{\prime} \omega_{2} \\
& \varepsilon^{\prime \prime}=\varepsilon_{1}^{\prime \prime}+a^{\prime \prime} \omega_{2} \\
& \varepsilon_{\infty}=\varepsilon_{1 \infty}+a_{\infty} \omega_{2}
\end{aligned}
$$

Here subscript 1and 2 assigned to the pure solvent and the solute respectively while subscript 0 referred to the zero frequency measurement in the static field and $\infty$ to the frequency measurement at a very high frequency. Concentration of the solute $\omega_{2}$ has been usually expressed in the units of mole fraction.

According to Higasi method [14] the Debye equation for $\mathrm{s}$ single relaxation time for the dilute solute solutions in a solvent is expressed as,

$$
\begin{aligned}
& \frac{a^{\prime}-a_{\infty}}{a_{0}-a_{\infty}}=\frac{1}{1+\omega^{2} \tau^{2}} \\
& \frac{a^{\prime \prime}}{a_{0}-a_{\infty}}=\frac{1}{1+\omega^{2} \tau^{2}}
\end{aligned}
$$

Where $a^{\prime}, a^{\prime \prime}, a_{0}$ and $a_{\infty}$ were obtained from the Eqs. (1) to (4), $\omega$ and $\tau$ refers to the angular frequency and the molecular relaxation time respectively. Combination of Eqs. (5) and (6) gives the following two independent equations

$$
\begin{aligned}
\tau_{1} & =\frac{1}{\omega} \frac{a^{\prime \prime}}{a^{\prime}-a_{\infty}} \\
\tau_{2} & =\frac{1}{\omega} \frac{a_{0}-a^{\prime}}{a^{\prime \prime}} \\
\tau_{3} & =\sqrt{\tau_{1} \cdot \tau_{2}}
\end{aligned}
$$

Where $\tau_{1}$ is average relaxation time, $\tau_{2}$ is overall relaxation time and $\tau_{3}$ is a geometric mean relaxation time.

According to Eyring [15], the molecular rotation needed sufficient activation energy to prevail over the energy barrier split the two mean equilibrium positions with opposite directions of the dipole and hence the relaxation time is given by the rate equation

$$
\begin{aligned}
\tau & =\frac{h}{k T} \exp \left(\frac{\Delta F_{\tau}}{R T}\right) \\
\eta & =\frac{N h}{V} \exp \left(\frac{\Delta F_{\eta}}{R T}\right)
\end{aligned}
$$

Where $F_{\tau}$ is activation energy for relaxation, $F_{\eta}$ is the molar activation energy of viscosity, $h$ is Planck's constant, $\mathrm{R}$ is gas constant, $\mathrm{k}$ is Boltzmann constant, $\mathrm{V}$ is molar volume and $\mathrm{T}$ is the absolute temperature.

\section{RESUltS AND DISCUSSION}

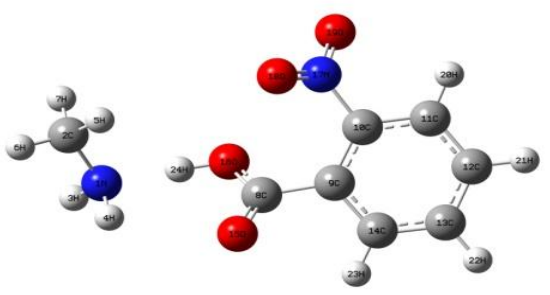

Figure 1: Optimized structure of ma2nba and atomic labeling 


\subsection{Optimized geometry}

The molecular structure of ma2nba is optimized using Gaussian 09W. The numbering of molecular structure shown in Fig 1. The optimization is done by B3LYP method with 6$311++\mathrm{G}(\mathrm{d}, \mathrm{p})$ basic set. The C8-C9, C9-C14, C10-C11, C12-
C13 bonds possesses high value. The value of bond length is $1.5400 \AA$. The highest bond angle influenced by C2, N1, H4 is $139.7796^{\circ}$. The bond length, bond angle and dihedral angle of the title molecule are tabulated for both basic set which is shown in table 1 .

Table 1: Optimized geometrical parameters (Bond Lengths, Bond Angles and Dihedral Angles) of ma2nba by B3LYP/6-311++G(d,p)

\begin{tabular}{|c|c|c|c|c|c|}
\hline Atoms & $\begin{array}{c}\text { Bond Length } \\
\left(\mathrm{A}^{\circ}\right)\end{array}$ & Atoms & $\begin{array}{c}\text { Bond Angle } \\
\left({ }^{\circ}\right)\end{array}$ & Atoms & $\begin{array}{c}\text { Dihedral Angle } \\
\left({ }^{\circ}\right)\end{array}$ \\
\hline $\mathrm{N} 1-\mathrm{C} 2$ & 1.4699 & C2-N1-H3 & 86.2965 & H3-N1-C2-H5 & 172.5625 \\
\hline $\mathrm{N} 1-\mathrm{H} 3$ & 1.0000 & $\mathrm{C} 2-\mathrm{N} 1-\mathrm{H} 4$ & 139.7796 & H3-N1-C2-H6 & 52.5701 \\
\hline N1-H4 & 1.0000 & C2-N1-H24 & 82.1289 & H3-N1-C2-H7 & -67.4396 \\
\hline N1-H24 & 1.5005 & H3-N1-H4 & 84.9300 & H4-N1-C2-H5 & 94.9007 \\
\hline $\mathrm{C} 2-\mathrm{H} 5$ & 1.0699 & H3-N1-H24 & 138.4943 & H4-N1-C2-H6 & -25.0916 \\
\hline $\mathrm{C} 2-\mathrm{H} 6$ & 1.0698 & H4-N1-H24 & 78.9334 & $\mathrm{H} 4-\mathrm{N} 1-\mathrm{C} 2-\mathrm{H} 7$ & -145.1010 \\
\hline $\mathrm{C} 2-\mathrm{H} 7$ & 1.0699 & N1-C2-H5 & 109.4645 & $\mathrm{H} 24-\mathrm{N} 1-\mathrm{C} 2-\mathrm{H} 5$ & 32.5180 \\
\hline $\mathrm{C} 8-\mathrm{C} 9$ & 1.5400 & N1-C2-H6 & 109.4736 & H24-N1-C2-H6 & -87.4743 \\
\hline C8-O15 & 1.2585 & $\mathrm{~N} 1-\mathrm{C} 2-\mathrm{H} 7$ & 109.4632 & $\mathrm{H} 24-\mathrm{N} 1-\mathrm{C} 2-\mathrm{H} 7$ & 152.5160 \\
\hline C8-O16 & 1.4300 & H5-C2-H6 & 109.4672 & C2-N1-O16-C8 & 173.1001 \\
\hline C9-C10 & 1.3551 & $\mathrm{H} 5-\mathrm{C} 2-\mathrm{H} 7$ & 109.4769 & H3-N1-O16-C8 & 97.8514 \\
\hline C9-C14 & 1.5400 & H6-H2-H7 & 109.482 & H4-N1-O16-C8 & 28.7619 \\
\hline $\mathrm{C} 10-\mathrm{C} 11$ & 1.5400 & C9-C8-O15 & 119.9906 & O15-8-C9-C10 & 0.0209 \\
\hline C10-N17 & 1.4700 & C9-C8-O16 & 120.0059 & O15-8-C9-C14 & -179.973 \\
\hline C11-C12 & 1.3552 & O15-C8-O16 & 120.0034 & O16-C8-C9-C10 & -179.981 \\
\hline C11-H20 & 1.0699 & C8-C9-C10 & 119.9854 & O16-C8-C9-C14 & 0.0255 \\
\hline $\mathrm{C} 12-\mathrm{C} 13$ & 1.5400 & C8-C9-C14 & 120.0162 & C9-C8-O15-O18 & -0.0774 \\
\hline C12-H21 & 1.0701 & C10-C9-C14 & 119.9984 & O16-C8-O15-O18 & 179.9241 \\
\hline $\mathrm{C} 13-\mathrm{C} 14$ & 1.3553 & C9-C10-C11 & 120.0029 & C9-C8-O16-H24 & 150.011 \\
\hline $\mathrm{C} 13-\mathrm{H} 22$ & 1.0700 & C9-C10-N17 & 119.9878 & O15-C8-O16-H24 & -29.9904 \\
\hline $\mathrm{C} 14-\mathrm{H} 23$ & 1.0699 & C11-C10-N17 & 120.0093 & C8-C9-C10-C11 & -179.989 \\
\hline O16-H24 & 0.9593 & C10-C11-C12 & 120.0052 & C8-C9-C10-N17 & 0.0122 \\
\hline N17-O18 & 1.1968 & $\mathrm{C} 10-\mathrm{C} 11-\mathrm{H} 20$ & 119.9995 & C14-C9-C10-C11 & 0.0051 \\
\hline N17-O19 & 1.3601 & $\mathrm{C} 12-\mathrm{C} 11-\mathrm{H} 20$ & 119.9953 & C14-C9-C10-N17 & -179.994 \\
\hline- & - & C11-C12-C13 & 119.9922 & C8-C9-C14-C13 & -179.998 \\
\hline- & - & $\mathrm{C} 11-\mathrm{C} 12-\mathrm{H} 21$ & 120.0010 & C8-C9-C14-H23 & 0.0014 \\
\hline- & - & $\mathrm{C} 13-\mathrm{C} 12-\mathrm{H} 21$ & 120.0068 & C10-C9-C14-C13 & 0.0080 \\
\hline- & - & C12-C13-C14 & 120.0011 & C10-C9-C14-C23 & -179.993 \\
\hline- & - & $\mathrm{C} 12-\mathrm{C} 13-\mathrm{H} 22$ & 119.9971 & C9-C10-C11-C12 & -0.0195 \\
\hline- & - & $\mathrm{C} 14-\mathrm{C} 13-\mathrm{H} 22$ & 120.0018 & C9-C10-C11-H20 & 179.9852 \\
\hline- & - & C9-C14-C13 & 120.0002 & N17-C10-C11-C12 & 179.9795 \\
\hline- & - & C9-C14-H23 & 119.9975 & N17-C10-C11-H20 & -0.0159 \\
\hline
\end{tabular}




\begin{tabular}{|c|c|c|c|c|c|}
\hline- & - & $\mathrm{C} 13-\mathrm{C} 14-\mathrm{H} 23$ & 120.0023 & C9-C10-N17-O18 & 0.0331 \\
\hline- & - & C8-O15-O18 & 116.0232 & C9-C10-N17-O19 & -179.967 \\
\hline- & - & C8-O16-H24 & 109.4681 & C11-C10-N17-O18 & -179.966 \\
\hline- & - & C10-N17-O18 & 119.9893 & C11-C10-N17-O19 & 0.0338 \\
\hline- & - & C10-N17-O19 & 120.0107 & C10-C11-C12-C13 & 0.0200 \\
\hline- & - & O18-N17-O19 & 120.0000 & $\mathrm{C} 10-\mathrm{C} 11-\mathrm{C} 12-\mathrm{H} 21$ & -179.98 \\
\hline- & - & O15-O18-N17 & 124.0235 & $\mathrm{H} 20-\mathrm{C} 11-\mathrm{C} 12-\mathrm{C} 13$ & -179.985 \\
\hline- & - & - & - & $\mathrm{H} 20-\mathrm{C} 11-\mathrm{C} 12-\mathrm{H} 21$ & 0.0152 \\
\hline- & - & - & - & C11-C12-C13-C14 & -0.0069 \\
\hline- & - & - & - & $\mathrm{C} 11-\mathrm{C} 12-\mathrm{C} 13-\mathrm{H} 22$ & 179.995 \\
\hline- & - & - & - & H21-C12-C13-C14 & 179.9933 \\
\hline- & - & - & - & $\mathrm{H} 21-\mathrm{C} 12-\mathrm{C} 13-\mathrm{H} 22$ & -0.0048 \\
\hline- & - & - & - & C12-C13-C14-C9 & -0.0075 \\
\hline- & - & - & - & $\mathrm{C} 12-\mathrm{C} 13-\mathrm{C} 14-\mathrm{H} 23$ & 179.9931 \\
\hline- & - & - & - & H22-C13-C14-C9 & 179.9906 \\
\hline- & - & - & - & $\mathrm{H} 22-\mathrm{C} 13-\mathrm{C} 14-\mathrm{H} 23$ & -0.0089 \\
\hline- & - & - & - & C8-O15-O18-N17 & 0.1283 \\
\hline- & - & - & - & C10-N17-O18-O15 & -0.0999 \\
\hline - & - & - & - & O19-N17-O18-O15 & 179.9004 \\
\hline
\end{tabular}

\subsection{FMO analysis}

The frontier molecular orbital plays an important role for the electric and optical properties, as well as for chemical reactions [16]. The LUMO of $\pi$ nature i.e: benzene ring is delocalized over the whole $\mathrm{C}-\mathrm{C}$ bond by contrasting the HOMO which is sited above methyl groups; as a result the $\mathrm{HOMO} \rightarrow$ LUMO transition implies that the transfer of electron density to $\mathrm{C}-\mathrm{C}$ bond of the benzene ring from methyl groups [17,18]. Fig. 10 shows the atomic orbital HOMO-LUMO composition of ma2nba which has been theoretically stimulated at DFT B3LYP/6-311++G (d,p) level. It indicates that the energy difference replicate the chemical activity of the title molecule LUMO as an electron acceptor which represents the capability to donate an electron and made strong change transfer interaction. The calculations show that the title molecule ma2nba has occupied molecular orbitals $[19,20]$.

$$
\begin{array}{ll}
\mathrm{E}_{\text {Hомо }}=-7.5087 \mathrm{eV} \\
\mathrm{E}_{\text {Luмо }}=-2.6225 \mathrm{eV} \\
\mathrm{E} & =4.8862 \mathrm{eV}
\end{array}
$$

A lowering of the HOMO and LUMO energy gap explains the eventual charge transfer interactions taking place within the molecule.

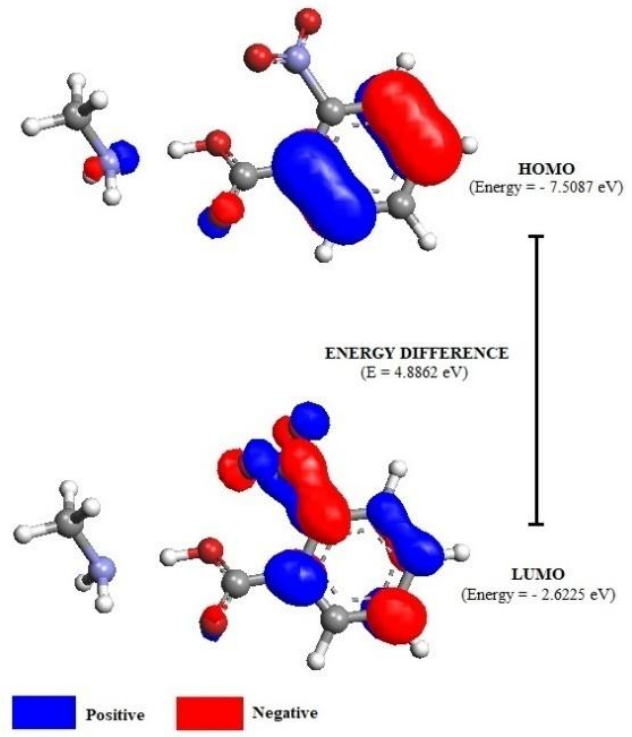

Figure 2: Calculated HOMO-LUMO Plots of ma2nba and energy difference of HOMO-LUMO

\subsection{Global chemical reactivity descriptor (GCRD)}

The global parameters like electro negativity, chemical potential, hardness and softness and local parameters like the Fukui function and electrophilicity are important on the prediction of the reactivity among the 
molecules. Electron density is a property that includes all the details regarding the molecular species. The local philicity holds complete information of the global electrophilicity and supplementary knowledge of electronegativity furthermore provide the local and global softness, the hardness and consequently all of the identified chemical reactivity like global and local descriptors and selectivity. DFT provides the foundation for exact mathematical definitions of reactivity descriptors like electronegativity, softness, hardness, chemical potential etc. [21,22].

Table 2: The Global chemical reactivity descriptor of ma2nba

\begin{tabular}{lc}
\hline \multicolumn{1}{c}{ Reactivity Descriptors } & $\begin{array}{c}\text { B3LYP/6- } \\
\mathbf{3 1 1 + +} \mathbf{G}(\mathbf{d}, \mathbf{p})\end{array}$ \\
\hline Electronic energy (hartree) & -721.4118 \\
HOMO & -7.5087 \\
LUMO & -2.6225 \\
E $_{\text {HOMO }-E_{\text {LUMO }}}$ & -4.8862 \\
Ionization potential $(\mathrm{I})$ & 7.5087 \\
Electron affinity $(\mathrm{A})$ & 2.6225 \\
Chemical potential $(\mu)$ & -5.0656 \\
Electron negativity $(\chi)$ & 5.0656 \\
Absolute hardness $(\eta)$ & 2.4431 \\
Softness $(\mathrm{S})$ & 0.4093 \\
Electrophilicity index $(\omega)$ & 5.2516 \\
Additional electronic charge $\left(\Delta N_{\max }\right)$ & 2.0734 \\
\hline
\end{tabular}

\subsection{Molecular electrostatic potential (MEP)}

Studying MEP gives information about the relationship between physicochemical properties and correlation of molecular structures. Also it helps to analysis the correlation between molecular structures with its physiochemical properties together with biomolecules and drugs.[23-25] The electrostatic potential of ma2nba is plotted for at B3LYP/6$311++\mathrm{G}(\mathrm{d}, \mathrm{p})$ basis set which is shown in Fig. 3a. The various values electrostatic potential of the surface are indicated by various colors, the negative region is preferred location for electrophilic reactivity, which is shown red and yellow region. The positive region is preferred for nucleophilic reactivity, which is shown blue region. Green colour indicates zero potentials. In this work, the calculated outcome shows that the negative potentials are over the electron negative oxygen atoms and positive potential are over the nucleophilic reactive hydrogen atoms [26,27]. This provides information for the region from where the mixture can have intermolecular interaction. The contour map of electrostatic of ma2nba has been constructed at B3LYP/6$311++\mathrm{G}(\mathrm{d}, \mathrm{p})$ levels and shown in figure $3 \mathrm{~b}$. It also confirms the different positive and negative potential with electron density surface [28,29].
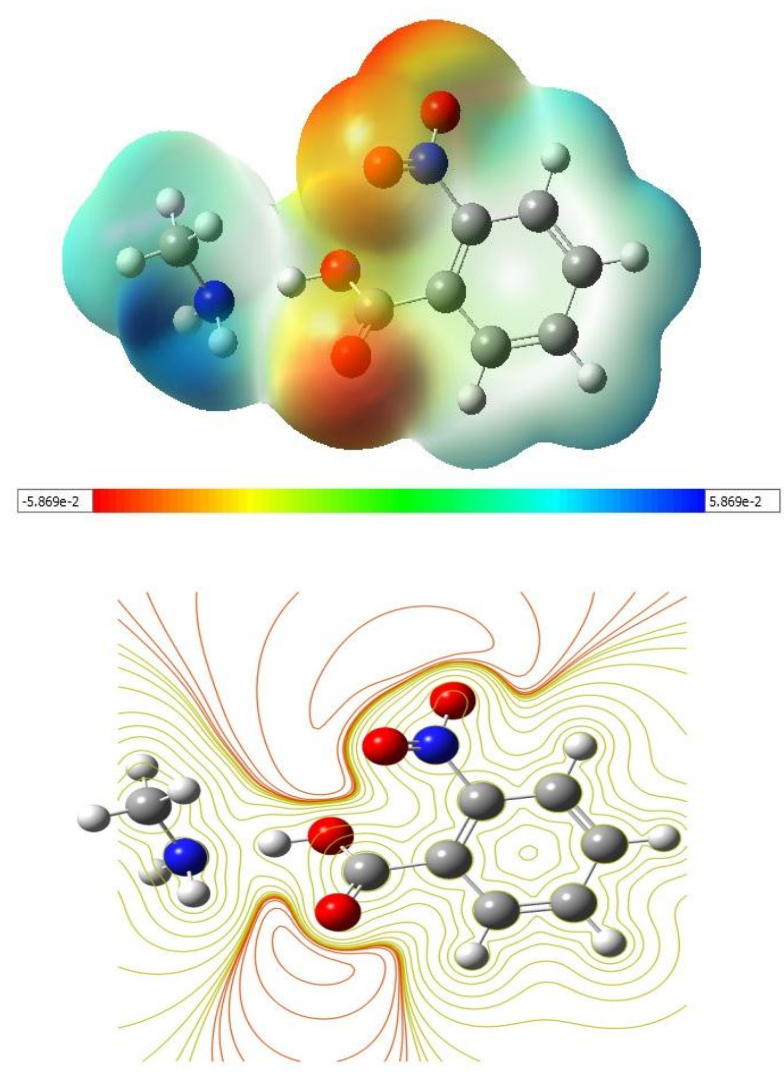

Figure 3: $M E P$ and Contour map of ma2nba at using B3LYP/6.311++ G(d,p)

\subsection{Muliken atomic charges and Natural charges}

The Mulliken atomic charges play a significant part to describe electronic characteristics of molecular system [30]. A comparative study on the distribution of Mulliken atomic charge and natural charges of the molecule is determined at B3LYP/6-311++G(d,p) basic set. The Mulliken atomic charges and natural charges slightly deviated which are given in table 3 . The natural atomic charges are based on the theory of the natural population analysis.

Table 3: The charge distribution calculated by the Mulliken and natural bond orbital methods using B3LYP/6.311++ $G(d, p)$

\begin{tabular}{cccc}
\hline SI.No & $\begin{array}{c}\text { Atoms } \\
\text { (by } \\
\text { number) }\end{array}$ & $\begin{array}{c}\text { Atomic } \\
\text { Charges } \\
\text { (Mulliken) }\end{array}$ & $\begin{array}{c}\text { Natural } \\
\text { Charges } \\
\text { (NBO) }\end{array}$ \\
\hline 1 & N1 & -0.643 & -0.9855 \\
2 & C2 & -0.362 & -0.3464 \\
3 & H3 & 0.258 & 0.3763 \\
4 & H4 & 0.282 & 0.4311 \\
5 & H5 & 0.179 & 0.1960 \\
6 & H6 & 0.132 & 0.1724 \\
7 & H7 & 0.157 & 0.1966
\end{tabular}




\begin{tabular}{cccc}
8 & C8 & -0.323 & 0.7873 \\
9 & C9 & 2.163 & -0.1285 \\
10 & C10 & -1.637 & 0.1223 \\
11 & C11 & -0.299 & -0.1726 \\
12 & C12 & -0.210 & -0.1726 \\
13 & C13 & -0.392 & -0.1659 \\
14 & C14 & -0.060 & -0.1664 \\
15 & O15 & -0.260 & -0.5290 \\
16 & O16 & -0.310 & -0.7390 \\
17 & N17 & -0.100 & 0.4271 \\
18 & O18 & 0.009 & -0.2369 \\
19 & O19 & 0.018 & -0.4689 \\
20 & H20 & 0.219 & 0.2445 \\
21 & H21 & 0.181 & 0.2153 \\
22 & H22 & 0.179 & 0.2127 \\
23 & H23 & 0.196 & 0.2329 \\
24 & H24 & 0.623 & 0.4971 \\
\hline
\end{tabular}

\subsection{Nonlinear optical (NLO) properties}

The field of non linear optics is the cutting edge of providing the key functions of frequency shifting, optical modulation, optical switching, optical logic and optical memory for the upcoming technologies in the area of signal processing, optical interconnections and telecommunications [31]. The electric dipole moments $(\mu)$, the polarizability $(\alpha)$ and the hyperpolarizability $(\beta)$ tensor components are calculated by B3LYP/6-311++G(d,p) basic set using Gaussian 09W software package. The equations for calculating the total dipole moment $(\mu)$, the mean polarizability $\left(\alpha_{0}\right)$, the anisotropy of the polarizability $(\Delta \alpha)$ and the mean first hyperpolarizability $\left(\beta_{0}\right)$ using the $\mathrm{x}, \mathrm{y}, \mathrm{z}$ components from Gaussian 09W output are as follows [32] and The calculated dipole moment $(\mu)$, polarizability $(\alpha)$, and hyperpolarizability $(\beta)$ values of ma2nba are given in Table 4.

$$
\begin{aligned}
\mu_{t o t}= & \left(\mu_{x}^{2}+\mu_{y}^{2}+\mu_{z}^{2}\right)^{\frac{1}{2}} \\
\alpha_{0}= & \frac{\left(\alpha_{x x}+\alpha_{y y}+\alpha_{z z}\right)}{3} \\
\Delta \alpha= & 2^{-\frac{1}{2}}\left[\left(\alpha_{x x}-\alpha_{y y}\right)^{2}+\left(\alpha_{y y}-\alpha_{z z}\right)^{2}+\right. \\
& \left.\left(\alpha_{z z}-\alpha_{x x}\right)^{2}\right]^{\frac{1}{2}} \\
\beta_{0}= & \left(\beta_{x}^{2}+\beta_{y}^{2}+\beta_{z}^{2}\right)^{\frac{1}{2}} \text { and } \\
\beta_{x}= & \left(\beta_{x x x}+\beta_{x y y}+\beta_{x z z}\right) \\
\beta_{y}= & \left(\beta_{y y y}+\beta_{x x y}+\beta_{y z z}\right) \\
\beta_{x}= & \left(\beta_{z z z}+\beta_{x x y}+\beta_{y y z}\right)
\end{aligned}
$$

Table 4: Nonlinear optical property data for ma2nba at DFT/B3LYP/6-31+G(d,p) level

\begin{tabular}{cccccc}
\hline Parameter & Hyperpolarizability & Parameter & Polarizability & Parameter & Dipole moment \\
\hline$\beta_{x x x}$ & 239.1901 & $\alpha_{x x}$ & 189.2377 & $\mu_{x}$ & -0.7002 \\
$\beta_{x x y}$ & -342.2544 & $\alpha_{x y}$ & 0.8175 & $\mu_{y}$ & -2.3949 \\
$\beta_{x y y}$ & 210.7499 & $\alpha_{y y}$ & 158.7033 & $\mu_{z}$ & -0.2409 \\
$\beta_{y y y}$ & -0.6099 & $\alpha_{x z}$ & 7.9362 & - & - \\
$\beta_{x x z}$ & 294.6246 & $\alpha_{y z}$ & 0.5408 & - & - \\
$\beta_{x y z}$ & -176.9755 & $\alpha_{z z}$ & 77.2583 & - & - \\
$\beta_{y y z}$ & 129.5916 & - & - & - & - \\
$\beta_{x z z}$ & 31.8362 & - & - & - & - \\
$\beta_{y z z}$ & -120.9970 & - & - & - & - \\
$\beta_{z z z}$ & -18.3258 & - & - & - & - \\
\hline
\end{tabular}

\subsection{FTIR Vibrational Assignments}

There are 24 atoms in ma2nba with symmetry of $\mathrm{C} 1$ point group. Hence, it has 66 (i.e., 3n-6) normal modes of vibrations. The vibrational modes viewed using Gaussian View 5.0.8 [33]. The unscaled frequencies are calculated and tabulated for the ground state with $\mathrm{d}$ and $\mathrm{p}$ orbitals by using B3LYP at 6.311++ level and tabulated in table 5. The FT-IR experimental frequencies of ma2nba are compared with the unscaled frequencies of B3LYP at 6.311++ level basic sets. The theoretical data obtained using Gabedit.exe 2.3.5 [34].

\subsubsection{COOH Vibrations}

The $\mathrm{O}-\mathrm{H}$ stretching frequency is characterized by a very broadband appearing near $3650-3580 \mathrm{~cm}^{-1}$. In addition, hydrogen bonded broadband appears at $3200-3550 \mathrm{~cm}^{-1}$. In the experimental FTIR spectrum hydrogen bonded $\mathrm{O}-\mathrm{H}$ stretching is observed at $3589.60 \mathrm{~cm}^{-1}$ it is negatively deviated to $\approx 39 \mathrm{~cm}^{-1}$. However the theoretically calculated wave number pertaining to $\mathrm{O}-\mathrm{H}$ stretching observed at $3559.50 \mathrm{~cm}^{-1}$ is positively deviated to $\approx 9 \mathrm{~cm}^{-1}$. The C-O stretching is a characteristic frequency of carboxylic acid is 
assigned to $1690 \mathrm{~cm}^{-1}$ [35]. The C-O stretching vibration band appearing at $1641.86 \mathrm{~cm}^{-1}$ and $1599.17 \mathrm{~cm}^{-1}$ in experimental FTIR spectrum and theoretically computed FTIR respectively, which shows a deviation of $\pm 49-91 \mathrm{~cm}^{-1}$. It may be of mixing with $\mathrm{C}-\mathrm{OH}$ bending vibration. Usually, the peaks appeared at $1330-1430 \mathrm{~cm}^{-1}$ is assigned to $\mathrm{O}-\mathrm{H}$ in plane bending, the peak at $650-770 \mathrm{~cm}^{-1}$ is assigned to $\mathrm{O}-\mathrm{H}$ out of plane bending. $\mathrm{O}-\mathrm{H}$ in plane bending observed at $1365.62 \mathrm{~cm}^{-1}$ and $1389.87 \mathrm{~cm}^{-1}$ both for experimental and theoretical spectrum. And $\mathrm{O}-\mathrm{H}$ out of plane bending observed at $612.88 \mathrm{~cm}^{-1}$ and $740.62 \mathrm{~cm}^{-1}$ for both for experimental and theoretical spectrum, there may be slight deviations in the wave number which is due to the fact that $\mathrm{O}-\mathrm{H}$ out-of-plane bending vibration mixes with $\mathrm{NO}_{2}$ inversion mode

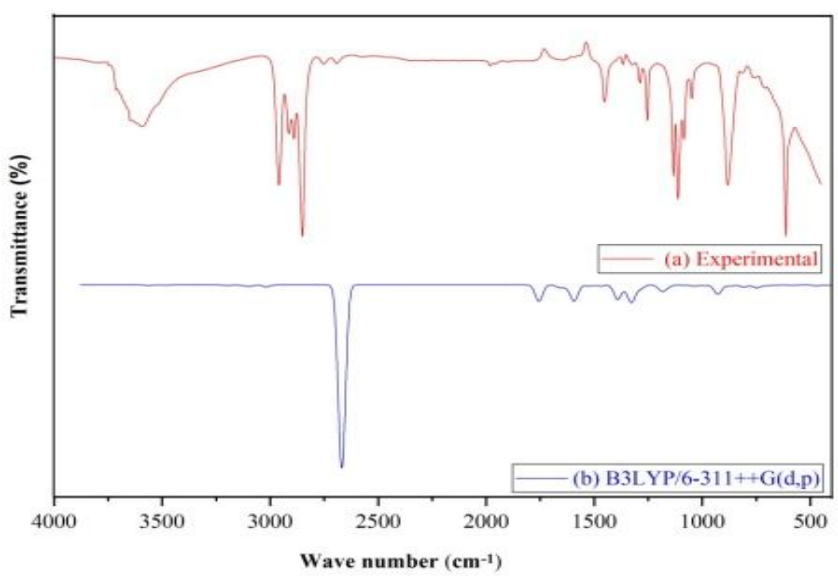

Figure 4: FTIR spectrum of ma2nba (a) Experimental (b) Theoretical (B3LYP/6-311++G(d,p))

\subsubsection{N-H vibrations}

$\mathrm{N}-\mathrm{H}$ absorption is observed in the $3400-3500 \mathrm{~cm}^{-1}$ region. For primary aliphatic amines display two well defined peaks due to asymmetric and symmetric $\mathrm{N}-\mathrm{H}$ stretching separated by $80 \mathrm{~cm}^{-1}$ to $100 \mathrm{~cm}^{-1}$. In experimental ftir spectra, peaks at $3651.14 \mathrm{~cm}^{-1}$ and $3595 \mathrm{~cm}^{-1}$ are observed, which are not distinct peaks but observed broaden, N-H stretching is weaker than $\mathrm{O}-\mathrm{H}$ so $\mathrm{N}-\mathrm{H}$ peak may be merged with $\mathrm{O}-\mathrm{H}$. The peaks $3485.36 \mathrm{~cm}^{-1}, 3533.78 \mathrm{~cm}^{-1}$ are theoretically observed using B3LYP. And the experimental and theoretical wave numbers are good agreement expected values. In addition, $\mathrm{NH}_{2}$ out-of-plane wagging band observed at $650 \mathrm{~cm}^{-1}-900 \mathrm{~cm}^{-1}$, experimentally $\mathrm{NH}_{2}$ wagging peaks observed at $880.13 \mathrm{~cm}^{-1}$ and $762.02 \mathrm{~cm}^{-1}$ and theoretical N-H wagging peak observed at $915.46 \mathrm{~cm}^{-1}$ and is positivily deviated to $\approx 15[36,37]$.

\subsubsection{C-N, C-O vibrations}

Peaks at $1000 \mathrm{~cm}^{-1}$ to $1250 \mathrm{~cm}^{-1}$ are assigned for aliphatic amines, for ma2nba molecule there are peaks observed at $1250.342 \mathrm{~cm}^{-1}$ which belongs to $\mathrm{C}-\mathrm{N}$ stretching. And $1184.67 \mathrm{~cm}^{-1}$ is observed from the theoretical FTIR spectrum. This is good agreement with the expected peaks. C-O Stretching and bending frequencies are usually in the range of $1044 \mathrm{~cm}^{-1}-1180 \mathrm{~cm}^{-1}$ [38-40], 1000-1090 [38,41] respectively. The peak observed at $1134 \mathrm{~cm}^{-1}$ for $\mathrm{C}-\mathrm{O}$ stretching in the experimental FTIR spectra and very weak absorption observed at $1027.08 \mathrm{~cm}^{-1}$ in the theoretical spectrum. For C-O bending vibrations, $1044.47 \mathrm{~cm}^{-1}$ peak observed experimentally and $1039.14 \mathrm{~cm}^{-1}$ peak observed in the theoretical FTIR spectrum.

\subsubsection{C-H stretching/bending}

$\mathrm{C}-\mathrm{H}$ stretching frequency is usually observed at $2800 \mathrm{~cm}^{-1}$ $3000 \mathrm{~cm}^{-1}[38,39], 2958.79 \mathrm{~cm}^{-1}$ peak observed in the experimental FTIR and it is fitted in the usual range of $\mathrm{C}-\mathrm{H}$ stretching. Moreover, $1431 \mathrm{~cm}^{-1}[38,42,40]$ peak assigned for $\mathrm{C}-\mathrm{H}$ bending, $1453.07 \mathrm{~cm}^{-1}$ is experimentally observed peak which is positively deviated to $\approx 22 \mathrm{~cm}^{-1}$. And 1392.34 $\mathrm{cm}^{-1}$ peak is observed theoretically which is negatively deviated to $39 \mathrm{~cm}^{-1}$. In both, $\mathrm{C}-\mathrm{H}$ stretching and bending the theoretical values of satisfactory agreement with the experimental FTIR values.

Table.5: Vibrational assignments of ma2nba at B3LYP/6-311++G(d,p)

\begin{tabular}{|c|c|c|}
\hline Experimental & Theoretical & \\
\hline FTIR frequency & $\begin{array}{l}\text { FTIR frequency } \\
\text { (Unscaled) }\end{array}$ & Assignment $\mathrm{PED} \geq 10 \%$ \\
\hline \multirow[t]{7}{*}{3589.00} & 3561.27 & $v \mathrm{NH}(99)$ \\
\hline & 3483.36 & $v \mathrm{NH}(99)$ \\
\hline & 3212.65 & $v \mathrm{CH}(89)$ \\
\hline & 3201.75 & $v \mathrm{CH}(94)$ \\
\hline & 3191.45 & $v \mathrm{CH}(94)$ \\
\hline & 3177.33 & vCH(92) \\
\hline & 3119.78 & vCH(99) \\
\hline
\end{tabular}




\begin{tabular}{|c|c|c|}
\hline 2958.70 & 3089.71 & vCH(100) \\
\hline 2914.51 & 3017.18 & $v \mathrm{CH}(100)$ \\
\hline 2696.03 & 2668.17 & vOH(89) \\
\hline \multirow[t]{10}{*}{1899.56} & 1756.02 & vOC(76) \\
\hline & 1661.44 & $\beta \mathrm{HNH}(52)+\tau \mathrm{HNHC}(42)$ \\
\hline & 1646.20 & $v \mathrm{CC}(39)+\beta \mathrm{CCC}(10)$ \\
\hline & 1615.81 & $v \mathrm{CC}(50)$ \\
\hline & 1591.65 & $v \mathrm{ON}(78)$ \\
\hline & 1532.71 & $\beta \mathrm{HOC}(32)+\beta \mathrm{NHO}(14)$ \\
\hline & 1517.33 & $\beta \mathrm{HCH}(77)$ \\
\hline & 1505.23 & $\beta \mathrm{HCC}(39)$ \\
\hline & 1501.66 & $\beta \mathrm{HCH}(57)+\tau \mathrm{HCHN}(14)$ \\
\hline & 1471.76 & $v \mathrm{CC}(21)+\beta \mathrm{HCC}(47)$ \\
\hline \multirow[t]{2}{*}{1453.99} & 1462.67 & $\beta \mathrm{HCH}(77)$ \\
\hline & 1391.37 & $\nu \mathrm{ON}(77)+\beta \mathrm{ONO}(12)$ \\
\hline \multirow[t]{2}{*}{1365.20} & 1345.01 & $v \mathrm{CC}(11)+\beta \mathrm{HNH}(10)+\tau \mathrm{HNHC}(17)$ \\
\hline & 1342.22 & $v \mathrm{CC}(57)+\tau \mathrm{HNHC}(10)$ \\
\hline 1321.88 & 1326.16 & $v \mathrm{OC}(27)+v \mathrm{CC}(17)+\beta \mathrm{HCC}(12)$ \\
\hline \multirow[t]{5}{*}{1285.51} & 1284.62 & $v \mathrm{CC}(15)+v \mathrm{OC}(10)+\beta \mathrm{HCC}(47)$ \\
\hline & 1195.42 & $\beta \mathrm{HNH}(11)+\beta \mathrm{HCH}(28)+\tau \mathrm{HCHN}(34)$ \\
\hline & 1187.38 & $\beta \mathrm{HCC}(67)$ \\
\hline & 1182.21 & $\beta \mathrm{CNH}(15)+\beta \mathrm{NHO}(12)+\tau \mathrm{HOCC}(17)+\tau \mathrm{CNHO}(16)$ \\
\hline & 1163.30 & $v \mathrm{CC}(26)+v \mathrm{NC}(13)+\beta \mathrm{HCC}(21)$ \\
\hline 1130.67 & 1157.24 & $v \mathrm{CC}(27)+v \mathrm{OC}(17)+\beta \mathrm{HCC}(21)$ \\
\hline 1083.07 & 1092.48 & $v \mathrm{NC}(12)+\beta \mathrm{CCC}(25)+\beta \mathrm{CCC}(17)$ \\
\hline \multirow[t]{7}{*}{1046.70} & 1057.72 & $v \mathrm{CC}(73)$ \\
\hline & 1036.79 & vNC(93) \\
\hline & 1008.08 & $v \mathrm{HCCC}(76)$ \\
\hline & 988.87 & $\beta \mathrm{HNH}(15)+\tau \mathrm{HNHC}(37)+\tau \mathrm{HCHN}(32)$ \\
\hline & 979.32 & $\tau \mathrm{HCCC}(85)$ \\
\hline & 927.90 & $\beta \mathrm{HNH}(36)+\beta \mathrm{HCH}(11)+\tau \mathrm{HCHN}(19)$ \\
\hline & 902.67 & $\tau \mathrm{HCCC}(71)$ \\
\hline \multirow[t]{2}{*}{882.78} & 873.15 & $v \mathrm{NC}(11)+\beta \mathrm{ONO}(45)+\beta \mathrm{CCC}(11)$ \\
\hline & 814.03 & $v \mathrm{OC}(12)+v \mathrm{CC}(13)+\beta \mathrm{OCO}(20)+\beta \mathrm{CCC}(18)$ \\
\hline \multirow[t]{2}{*}{807.63} & 806.90 & $\tau \mathrm{HCCC}(22)+\sigma \mathrm{OCOC}(41)+\sigma \mathrm{CCCC}(15)$ \\
\hline & 804.14 & $\tau \mathrm{HCCC}(24)+\sigma \mathrm{OCON}(30)+\sigma \mathrm{NCCC}(17)$ \\
\hline 764.57 & 747.84 & $\tau \mathrm{HCCC}(34)+\sigma \mathrm{OCOC}(16)+\sigma \mathrm{OCON}(26)$ \\
\hline \multirow[t]{2}{*}{707.61} & 708.59 & $\beta \mathrm{ONO}(12)+\tau \mathrm{CCCC}(32)+\sigma \mathrm{OCON}(10)$ \\
\hline & 699.78 & $\beta \mathrm{OCO}(18)+\beta \mathrm{CC}(11)+\tau \mathrm{CCCC}(21)$ \\
\hline \multirow[t]{3}{*}{609.74} & 658.45 & $\beta \mathrm{CCC}(11)+\beta \mathrm{OCO}(11)+\beta \mathrm{CCC}(49)$ \\
\hline & 589.36 & $\beta \mathrm{ONC}(34)+\beta \mathrm{OCC}(17)$ \\
\hline & 562.43 & $\beta \mathrm{OCC}(17)+\tau \mathrm{CCCC}(15)+\sigma \mathrm{CCCC}(10)$ \\
\hline
\end{tabular}


471.25

421.00

414.32

370.69

351.43

266.79

241.56

194.54

179.76

158.61

118.76

107.88

96.00

64.98

39.68

31.67

26.24 $\beta \mathrm{HNH}(29)+\beta \mathrm{HOC}(10)+\tau \mathrm{HNHC}(45)$

$v \mathrm{CC}(15)+v \mathrm{NC}(15)+\beta \mathrm{CCC}(12)$

$\tau \mathrm{CCCC}(46)$

$\beta \mathrm{ONC}(19)+\beta \mathrm{OCC}(20)+\tau \mathrm{CCCC}(18)$

$v \mathrm{NH}(14)+v \mathrm{CC}(13)+v \mathrm{NC}(20)$

$\beta \mathrm{CCC}(31)+\beta \mathrm{NCC}(22)$

$v \mathrm{NH}(32)+\beta \mathrm{NCC}(14)$

$\beta \mathrm{NCC}(14)+\sigma \mathrm{CCCC}(17)$

$v \mathrm{NH}(13)+\tau \mathrm{HCHN}(22)+\tau \mathrm{HCHN}(34)$

$\sigma \mathrm{NCCC}(38)$

$\beta \mathrm{CNH}(19)+\tau \mathrm{CCCC}(13)$

$\beta \mathrm{CNH}(19)+\tau \mathrm{NHOC}(10)+\tau \mathrm{OCCC}(12)$

$\beta \mathrm{NHO}(17)+\tau \mathrm{ONCC}(22)$

$\beta \mathrm{NHO}(13)+\tau \mathrm{NHOC}(10)+\tau \mathrm{CNHO}(22)+\sigma \mathrm{CCCC}(12)$

$\tau \mathrm{NHOC}(26)+\tau \mathrm{ONCC}(37)+\tau \mathrm{OCCC}(11)$

$\beta \mathrm{NHO}(11)+\tau \mathrm{HOCC}(16)+\tau \mathrm{OCCC}(32)+\tau \mathrm{CNHO}(19)$

$\tau \mathrm{HOCC}(30)+\tau \mathrm{NHOC}(25)+\tau \mathrm{OCCC}(12)$

Proposed assignment and potential energy distribution (PED) vibrational modes: types of vibrations: $v$ - stretching, $\beta$ - in-plane bending, $\sigma$ - out plane bending, $\tau$ - torsion

\subsection{Dielectric relaxation studies}

Dielectric parameters like static dielectric constant, dielectric constant, dielectric loss are used to determine average relaxation time $\left(\tau_{1}\right)$, overall dielectric relaxation $\left(\tau_{2}\right)$ and a geometric mean relaxation time $\left(\tau_{3}\right)$ using equation $7-9$. The relaxation times of title compounds calculated over five different molar ratios $(1: 3,1: 2,1: 1,2: 1,3: 1)$ at room temperature. According to Eyring [41] the process of molecular rotation requires an activation energy sufficient to overcome the energy barrier separating the two mean equilibrium positions with opposite directions of the dipole; and hence the activation energy for is calculated by the rate equation 10. Because the present work is based on Higasi's method. Higasi felt that the Debye equations for determining relaxation time is valid because it is based on a' and a" which are slopes defined by the equation 1-4. The effects of viscosity on the relaxation time have also been studied [42], it observed that with increasing concentration of solutes (methylamine and 2-nitrobenzoic acid) in 1,4-dioxane viscosities decreases and the value of viscosity found high in the equimolar ratio of solute. In accordance with the variation of viscosities influences $\tau$ values is in of order; $1: 3<1: 2<1: 1>2: 1>3: 1$ and it is given in table 6 .

Table 6: Value of dielectric constants and relaxation times of methylamine with 2-nitro benzoic acids in 1,4 - Dioxane at different weight fractions

\begin{tabular}{ccccccccc}
\hline \multirow{2}{*}{ Ratio } & \multirow{2}{*}{$\boldsymbol{W}_{\mathbf{2}}$} & \multirow{2}{*}{$\boldsymbol{\varepsilon}_{\mathbf{0}}$} & $\boldsymbol{\varepsilon}$ & \multirow{2}{*}{$\boldsymbol{\varepsilon}^{\prime \prime}$} & $\boldsymbol{\varepsilon}_{\infty}$ & \multicolumn{3}{c}{ Relaxation Time } \\
\cline { 7 - 9 } & & & & & $\boldsymbol{\tau}_{\boldsymbol{1}}$ & $\boldsymbol{\tau}_{\mathbf{2}}$ & $\boldsymbol{\tau}_{\mathbf{0}}$ \\
\hline $1: 3$ & 0.020 & 3.102 & 2.551 & 0.363 & 2.186 & 23.467 & 25.278 & 24.356 \\
$1: 2$ & 0.023 & 3.116 & 2.537 & 0.346 & 2.193 & 24.313 & 27.803 & 26.000 \\
$1: 1$ & 0.030 & 3.146 & 2.526 & 0.344 & 2.202 & 26.463 & 29.977 & 28.165 \\
$2: 1$ & 0.037 & 3.114 & 2.536 & 0.346 & 2.198 & 25.036 & 27.738 & 26.353 \\
$3: 1$ & 0.040 & 3.101 & 2.552 & 0.362 & 2.192 & 23.827 & 25.221 & 24.514 \\
\hline
\end{tabular}

The values of the group rotation relaxation time $\left(\tau_{2}\right)$ is maximum when comparing with $\left(\tau_{1}\right),\left(\tau_{3}\right)$ and this indicates that the contribution of intermolecular or overall molecular relaxation is larger in comparison to intramolecular or individual molecular relaxation in the systems [43]. The higher values of $\tau_{2}$ may be due to the increase in effective radius of the rotating unit. Also indicates that there is a complex formation in the form of intermolecular hydrogen bond between the $\mathrm{H}^{\delta+}$ of 2-nitro benzoic acid and $\mathrm{N}^{\delta-}$ in the amino group of methylamine as shown in Figure 5a. The 
other possibility of solute solvent interactions is also leads to intermolecular hydrogen bond between electropositive nature of the amino hydrogen atom and sp3 hybridized oxygen atom of 1,4 Dioxane which is shown in Figure 5b. Similar interactions also observed between hydroxyl hydrogen atom in 2-nitro benzoic acid and oxygen atom of 1,4 Dioxane shown in figure $5 \mathrm{c}$.
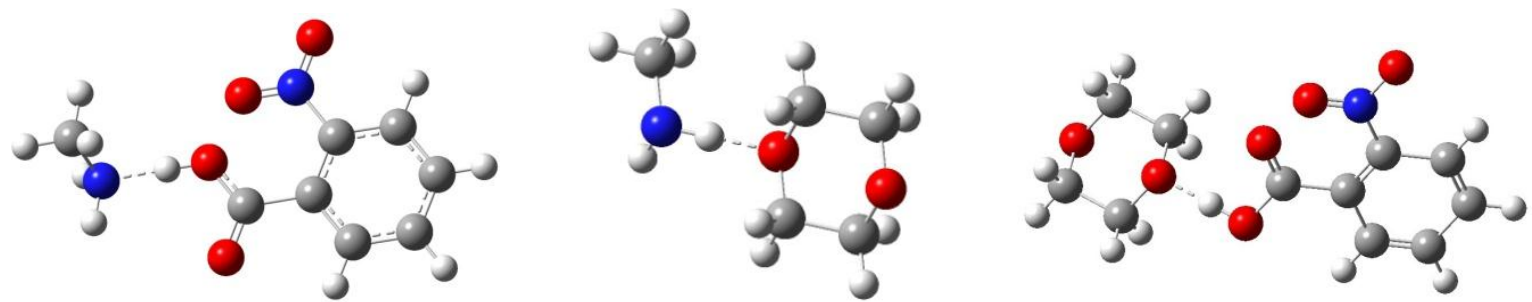

Figure 5: Intermolecular hydrogen between (a) methylamine + 2-nitro benzoic acid (b) methylamine + 1,4-dioxane and (c) 2nitro benzoic acid +1 ,4- dioxane

In our present study, the hydrogen bond analysis is also carried out by DFT (B3LYP)/6-31G (d,p) method. The hydrogen-bonded complex pertains to the understanding of interactions and a concerted application of experimental and theoretical methods can be used to obtain a clear picture of hydrogen bonding structures [44]. The selected molecular structure contains intramolecular $\mathrm{N}-\mathrm{H}$...... $\mathrm{N}$ interactions. In the title compound, atom $\mathrm{N} 1$ in the molecule acts as hydrogen bond donor, via atom $\mathrm{H} 3$ to atom $\mathrm{H} 24$. Hence, the hydrogen bond interaction between N10-H19.....Cl16 and H3-N1....H24 is observed. The distances between H19-Cl16 and $\mathrm{N} 1-\mathrm{H} 24$ are about $1.5005 \AA$ and it is the range less than $3.0 \AA$ for hydrogen interaction [45-46]. The other parameters i.e., the bond angles between the hydrogen bonding are also shown in Table 1.

\section{Conclusion}

For ma2nba molecule, the optimized molecular geometry, FMO, GCRD, MEP, NLO have been theoretically calculated in ground state. The value of HOMO-LUMO energy gap implies the possibility of intermolecular charge transfer in the molecule. Molecular surfaces, Mulliken atomic charges are compared with natural charges. Assignments of the vibrational bands were determined by potential energy distribution analysis and compared with experimental values. Using Higasi method, dielectric relaxation parameters like dielectric constant, dielectric loss, average and overall relaxation time, the molar free energy of activation for viscous flow and the molar free energy of dielectric relaxation of ma2nba have been calculated over five different molar ratios at room temperature.. These parameters were inferred in terms of molecular association in terms of hydrogen bonding in the mixture and the relaxation time found maximum at 1:1 molar ratio. Vibrational spectral analysis also confirms the existence of $\mathrm{H}-\mathrm{N} . . . \mathrm{H}$ intermolecular interaction. The study revealed complete information about molecular interaction of ma2nba molecule by theoretical and experimental methods.

\section{REFERENCES}

[1]. A. Courtney, P. Flatt, Chapter 5: Covalent Bonds and Introduction to Organic Molecules, Western Oregon University.

[2]. John T. Plati, Wilhelm Wenner, The Reaction of acetophenone with formaldehyde and Methylamine Hydrochloride. J. Org. Chem., 14(4), pp 543-549, 1949.

[3]. L. L. Simpson, Ammonium chloride and methylamine hydrochloride antagonize clostridial neurotoxins, JPET, 225 (3), pp 546-552, 1983.

[4]. Y. Hasegawa, et al, A novel degradative pathway of 2nitrobenzoate via 3-hydroxyanthranilate in Pseudomonas fluorescens strain KU-7. FEMS Microbiol Lett., 190(2), pp 185190, 2000.

[5]. G. Smith., et al. Molecular adducts of 2,6-diamino pyridine with nitro-substituted aromatic carboxylic acids and the crystal structure of the 1:1 adduct of 2,6-diaminopyridine with 2nitrobenzoic acid, Aust. J. Chem., 52(1), pp 71-74, 1999.

[6]. M. Peter, W. Gill, G.Benny, Johnson, John A. Pople, Michael J. Frisch, The performance of the Becke-Lee-Yang-Parr (B-LYP) density functional theory with various basis sets, Chemical Physics Letters, 197(4-5), pp 499-505, 1992.

[7]. C. Lee, W. Yang, R. G. Parr, Development of the Colle-Salvetti correlation-energy formula into a functional of the electron density, Phys. Rev. B 37, pp 785-789, 1988.

[8]. M. Karabacak, D. Karagöz, M. Kurt, Experimental (FT-IR and FT-Raman spectra) and theoretical (ab initio HF, DFT) study of 2-chloro-5-methylaniline, J. Mol. Struct. 892, pp 25-31, 2008.

[9]. M. Karabacak, M. Kurt, A. Atac, Experimental and theoretical FT- IR and FT- Raman spectroscopic analysis of N1- methyl- 2- chloroaniline, J. Phys. Org. Chem. 22, pp 321330, 2009.

[10]. Gaussian $₫ 09 w$, Version 7.0, copyright $@$ (C) 1995-09, Gaussian, Inc.

[11]. N. Karthikeyan, J. Joseph Prince, S. Ramalingam and S.Periandy, Spectroscopic [FT-IR and FT-Raman] and theoretical [UVVisible and NMR] analysis on $\alpha$-Methylstyrene by DFT calculations, Spectrochimica Acta Part A: Molecular and Biomolecular Spectroscopy, 143, pp 107-119, 2015.

[12]. S.Xavier and S.Periandy, Spectroscopic (FT-IR, FT-Raman, UV and NMR) investigation on 1-phenyl-2-nitropropene by quantum computational calculations, Spectrochimica Acta Part A: Molecular and Biomolecular Spectroscopy 149, pp 216-230, 2015. 
[13]. Mehmet Karabacak, Etem Kose, Ahmet Atac, Abdullah M. Asiri and Mustafa Kurt, Monomeric and dimeric structures analysis and spectroscopic characterization of 3,5-difluorophenylboronic acid with experimental (FT-IR, FT-Raman, ${ }^{1} \mathrm{H}$ and ${ }^{13} \mathrm{C}$ NMR, UV) techniques and quantum chemical calculations, Journal of Molecular Structure 1058. pp 79-96, 2014.

[14]. Y. Higasi, K. Koga and M. Nakamura, "Dielectric Relaxation and Molecular Structure - V. Application of the Single Frequency Method to Systems with two Debye Dispersions," Bull. Chem. Soc. Jap. 44, pp 988-992, 1971.

[15]. S. Glasstone, K. J. Laidler, H.Eyring, The Theory of Rate Process: The Kinetics of Chemical Reactions, Viscosity, Diffusion and Electrochemical Phenomena, McGraw Hill, New York, pp 19, 1941.

[16]. H. Eddine Ahmed, S. Kamoun, Crystal structure, vibrational spectra, optical and DFT studies of bis (3-azaniumylpropyl) azanium pentachloro antimonate (III) chloride monohydrate $\left(\mathrm{C}_{6} \mathrm{H}_{20} \mathrm{~N}_{3}\right) \quad \mathrm{SbCl}_{5} \cdot \mathrm{Cl} \cdot \mathrm{H}_{2} \mathrm{O}$, Spectrochimica Acta Part A: Molecular and Biomolecular Spectroscopy, 184, pp 38-46, 2017.

[17]. S. Sumathi, K. Viswanathan, S. Ramesh, FT-IR, FT-Raman and SERS Spectral Studies, HOMO-LUMO Analyses, Mulliken Population Analysis and Density Functional Theoretical Analysis of 1-Chloro 4-Fluorobenzene, IOSR Journal of Applied Physics, 8(1), Ver. II, pp 16-25, 2016.

[18]. M.V.S. Prasad, Kadali Chaitanya, N. Udaya Sri V.Veeraiah, Vibrational and electronic absorption spectral studies of 5-amino -1- (4-bromophenyl) -3-phenyl-1-H-pyrazole, Spectrochimica Acta Part A: Molecular and Biomolecular Spectroscopy, 99, pp 379-389, 2012.

[19]. S. Muthu, J. Uma Maheswari, Tom Sundius, Quantum mechanical, spectroscopic studies (FT-IR, FT-Raman, NMR, UV) and normal coordinates analysis on 3- ([2(diaminomethyleneamino) thiazol $-4-\mathrm{yl}]$ methylthio) $-\mathrm{N}^{\prime}-$ sulfamoyl propanimid amide Spectrochimica Acta Part A: Molecular and Biomolecular Spectroscopy, 108, pp 307-318, 2013.

[20]. Tuncay Karakurt Muharrem Dinçer Ahmet Çetin Memet Şekerci, Molecular structure and vibrational bands and chemical shift assignments of 4-allyl-5- (2 - hydroxyl phenyl $)-2,4$ - dihydro - $3 \mathrm{H}$ - 1,2,4-triazole-3-thione by DFT and $a b$ initio HF calculations, Spectrochimica Acta Part A: Molecular and Biomolecular Spectroscopy, 77(1), pp 189-198, 2010.

[21]. S. Muthu, J. Uma Maheswari, Tom Sundius, Molecular structural, non-linear optical, second order perturbation and Fukui studies of Indole-3-Aldehyde using density functional calculations, Spectrochimica Acta Part A: Molecular and Biomolecular Spectroscopy, 106, pp 299-309, 2013.

[22]. Pratim Kumar Chattaraj, Buddhadev Maiti, and Utpal Sarkar, Philicity, A Unified Treatment of Chemical Reactivity and Selectivity, J. Phys. Chem. A, 107 (25), pp 4973-4975, 2003.

[23]. V.P. Gupta, Chapter 6 - Electron Density Analysis and Electrostatic Potential, Principles and Applications of Quantum Chemistry, pp 195-214, 2016.

[24]. E. Scrocco, J. Tomasi (n.d.). The electrostatic molecular potential as a tool for the interpretation of molecular properties. New Concepts II, pp 95-170. doi:10.1007/3-540-06399-4_6 .

[25]. Sihem Medjahed, Salah Belaidi, Salim Djekhaba, Noureddine Tchouar and Aicha Kerassa, Computational Study of Molecular Electrostatic Potential, Drug Likeness Screening and StructureActivity/Property Relationships of Thiazolidine-2,4-Dione Derivatives, J. Bionanosci. 10(2), pp 118-126, 2016.

[26]. T.Abbaz, A.Bendjeddou, D.Villemin, Application of Reactivity Descriptors to the Benzenesulfonamide Derivatives, Journal of Scientific and Engineering Research, 6(2): pp 57-68, 2019.
[27]. A.Prabakaran, S. Muthu, Normal coordinate analysis and vibrational spectroscopy (FT-IR and FT-Raman) studies of (2S) -2-amino-3- (3,4-dihydroxyphenyl) -2-methyl propanoic acid using ab initio HF and DFT method, Spectrochimica Acta Part A: Molecular and Biomolecular Spectroscopy, 99(15), pp 90-96, 2012.

[28]. K.Gopinath, C.Karthikeyan, A.S.Haja Hameed, K.Arunkumar and A.Arumugam, Phytochemical Synthesis and Crystallization of Sucrose from the Extract of Gloriosa superba. Research Journal of Phytochemistry, 9: pp 144-160, 2015.

[29]. G.Subhapriya, S.Kalyanaraman, N.Surumbarkuzhali, S.Vijayalakshmi, V.Krishnakumar, S.Gandhimathi, Intermolecular hydrogen bonding, structural and vibrational assignments of 2, 3, 4, 5-tetrafluoro benzoic acid using density functional theory, Journal of Molecular Structure, 1128, pp 534543, 2017.

[30]. Himri Safia, Lafifi Ismahan, Guendouzi Abdelkrim, Cheriet Mouna, Nouar Leila, MadiFatiha, Density functional theories study of the interactions between host $\beta$-Cyclodextrin and guest 8-Anilinonaphthalene-1-sulfonate: Molecular structure, HOMO, LUMO, NBO, QTAIM and NMR analyses Journal of Molecular Liquids, 280, pp 218-229, 2019.

[31]. S.Suresh and D.Arivuoli, Synthesis, Optical and Dielectric Properties of Tris-Glycine Zinc Chloride (TGZC) Single Crystals, Journal of Minerals \& Materials Characterization \& Engineering, 10(6), pp 517-526, 2011.

[32]. Y.S. Priya, K.R.Rao, P.V.Chalapathi and A.Veeraiah, Vibrational and Electronic Spectra of 2-Phenyl-2-Imidazoline: A Combined Experimental and Theoretical Study, Journal of Modern Physics, 9, pp 753-774, 2018.

[33]. M.Ramalingam, N.Sundaraganesan, H.Saleem, J.Swaminathan, Experimental (FTIR and FT-Raman) and $a b$ initio and DFT study of vibrational frequencies of 5-amino-2-nitrobenzoic acid, Spectrochimica Acta Part A, 71, pp 23-30, 2008.

[34]. V. Arjunan, M. Kalaivani, R. Ravindran, S. Mohan. S. Structural, vibrational and quantum chemical investigations on 5-chloro-2hydroxy benzamide and 5-chloro-2-hydroxybenzoic acid, Spectrochimica Acta Part A: Molecular and Biomolecular Spectroscopy, 79(5), pp 1886-1895, 2011.

[35]. Kyle Gipson, Kathryn Stevens, Phil Brown, and John Ballato, Infrared Spectroscopic Characterization of Photoluminescent Polymer Nanocomposites, Journal of Spectroscopy, Article ID 489162, pp 1-9, 2015.

[36]. M. E. Yazdanshenas, M. Shateri-Khalilabad, One-step synthesis of superhydrophobic coating on cotton fabric by ultrasound irradiation, Ind. Eng. Chem. Res. 52, pp 12846-12854, 2013.

[37]. C. H. Xue, S. T. Jia, J. Zhang, L. Q. Tian, Superhydrophobic surfaces on cotton textiles by complex coating of silica nanoparticles and hydrophobization, Thin Solid Films 517, pp 4593-4598, 2019.

[38]. M. P. Gashti, F. Alimohammadi, A. Shamei, Preparation of water-repellent cellulose fibers using a polycarboxylic acid/hydrophobic silica nano composite coating, Surf. Coat. Technol. 206, pp 3208-3215, 2012.

[39]. Q. Gao, Q. Zhu, Y. Guo, Formation of highly hydrophobic surfaces on cotton and polyester fabrics using silica sol nanoparticles and nonfluorinated alkylsilane, Ind. Eng. Chem. Res. 48, pp 9797-9803, 2009.

[40]. A. L. Mohamed, M. A. El-Sheikh, A. I. Waly, Enhancement of flame retardancy and water repellency properties of cotton fabrics using silanol based nano composites, Carbohydr. Polym. 102, pp 727-737, 2014.

[41]. S. Glasstone, K. J. Laidler and H. Eyring, The Theory of Rate Processes, McGraw-Hill, New York (1941), Chapter 9. 
[42]. K. Chitoku and K. Higasi, This Bulletin, 36, 1064 (1963) ; K. Higasi, "Dipole Molecules and Chemistry," Hokkaido University, Sapporo (1965), Chapter 1; Krishnaji and A. Mansingh, J. Chem. Phys., 42, pp 2503, 1965.

[43]. S. M. Khameshara, M. S. Kavadia, M. S. Lodha, D. C. Mathur and V. K. Vaidya, Dielectric relaxation time and dipole moment of isometric butanols in benzene solutions, J.Mol. Liq. 26(2), pp $77-84,1983$

[44]. Y. Dimitrova, Structure and vibrational spectrum of the hydrogen-bonded system between 4-tert-butylphenol and $\mathrm{N}$ - bases: Ab initio and DFT studies, Spectrochim. Acta Part A Mol. Biomol. Spectrosc. 69 (2), pp 517-523, 2008.

[45]. G. A. Jaffrey, An Introduction to Hydrogen Bonding, Oxford University Press, New York, 1997.

[46]. G. B. Mathapati, P. K. Ingalagondi, Omnath Patil,

B. Shivaleela, Shivaraj Gounalli and S. M. Hanagodimath, Estimation of ground and excited state dipole moments of newly synthesized coumarin molecule by Solvatochromic shift method and Gaussian software, International Journal of Scientific Research in Physics and Applied Sciences, Vol.7, Issue.2, pp.3843, 2019. 